\title{
A Scanning Electron Microscopy Technique for Viewing Plant-Microbe Interactions at Tissue and Cell-Type Resolution
}

\author{
Denise Caldwell and Anjali S. Iyer-Pascuzzi ${ }^{\dagger}$ \\ Department of Botany and Plant Pathology, Center for Plant Biology, Purdue University, West Lafayette, IN 47907 \\ Accepted for publication 24 January 2019.
}

\begin{abstract}
Observing pathogen colonization and localization within specific plant tissues is a critical component of plant pathology research. Highresolution imaging, in which the researcher can clearly view the plant pathogen interacting with a specific plant cell, is needed to enhance our understanding of pathogen lifestyle and virulence mechanisms. However, it can be challenging to find the pathogen along the plant surface or in a specific cell type. Because of the time-consuming and expensive nature of high-resolution microscopy, techniques that allow a researcher to find a region of pathogen colonization more quickly at low resolution and subsequently move to a high-resolution microscope for detailed observation are needed. Here we present paraffin scanning electron microscopy

(PSEM), a technique in which paraffin-embedded samples are first sectioned to identify a region of interest. Subsequently the same block is recut, deparaffinized, and used in scanning electron microscopy (SEM) to generate high-resolution images of plant-pathogen interactions in specific plant cell types. This method has several additional advantages over traditional SEM techniques, including reduced noise and better image quality. Here we use this technique to show that Fusarium oxysporum f. sp. lycopersici colonization is restricted in resistant Solanum pimpinellifolium and that PSEM works well in additional pathosystems, including maize leaves and Clavibacter michiganensis subsp. nebraskensis and Arabidopsis leaves and Pseudomonas syringae.
\end{abstract}

Plant pathogens often predominantly colonize specific cell types and tissues within a plant. Observing the plant-microbe interaction at this level of resolution can be informative regarding resistance and susceptibility mechanisms and can reveal detailed information regarding a pathogen's lifestyle within the plant. However, it also can be technically challenging, time-consuming, and require expensive microscopes. In early stages of disease onset or in resistant plants, it may not always be clear where the pathogen is located. It can be challenging to find the pathogen along the surface of the organ (root, stem, or leaf) as well as within the organ in a specific cell type or tissue. This can lead to additional frustration and expenses with regard to both microscopy and a researcher's time. Methods that allow a researcher to identify a region of interest more quickly at low resolution and subsequently move to a highresolution microscope to observe the detailed plant-microbe interaction are needed. Here we present a method in which we section paraffin-embedded samples to first find a region of interest in a light microscope and subsequently use scanning electron microscopy (SEM) to generate high-resolution images of plantpathogen interactions in specific plant cell types. This method works well in roots, stems, and leaves, in both monocots and dicots, and for a variety of pathogens.

Although light microscopy is a useful tool for observing plant-microbe interactions, it lacks the resolution to observe these interactions in fine detail. Other microscopes, such as confocal scanning, can be used but require organisms to be tagged with fluorescent reporters. SEM allows the researcher to examine

†Corresponding author: A. S. Iyer-Pascuzzi; asi2@purdue.edu

Funding: This work was funded by a Foundation for Food and Agriculture Research grant, Hatch funds (project number IND011293), and Purdue University start-up funds, all to A. S. Iyer-Pascuzzi.

*The $e$-Xtra logo stands for "electronic extra" and indicates that three supplementary figures and one supplementary table are published online.

The author(s) declare no conflict of interest.

(C) 2019 The American Phytopathological Society plant-microbe interactions at high resolution without transforming the plant or microbe with a fluorescent reporter. In SEM, a highly focused beam of electrons moves across a sample. Electrons are reflected back to detectors, which collect and process the electrons into a three-dimensional image of the sample surface (Pathan et al. 2008). Variations in the sample surface topography result in differences in electron signal emission and can be observed as structural differences in the final image. Most electrons collected by the detector are low energy and from the sample surface, but occasionally high-energy backscattered electrons from below the surface are collected and can cause image distortions. To reduce this noise (also called charging), samples are typically covered with a special conductive coating that decreases backscattering of electrons.

There are several different types of SEM (for a review, see Pathan et al. 2008), including ambient temperature SEM and low temperature SEM (also known as cryo-scanning electron microscopy [CSEM]). In ambient temperature SEM, samples must be dehydrated, either with critical point drying (CPD) (Anderson 1951), freeze-drying, or other chemical methods. Among these, CPD is the most commonly used in plant pathology to observe plant-pathogen interactions (Fritschi et al. 2008; Koutsoudis et al. 2006; Mbofung et al. 2016; Sun et al. 2013). CPD works very well for plant cell surface features that are not sensitive to dehydration. The disadvantage with CPD is that samples are fragile and must be preserved for use only with ambient temperature SEM. Samples cannot be recut for additional SEM views below the sample surface, or recut for use with other microscopes.

CSEM is a type of SEM that is useful for specimens that would be damaged during dehydration (reviewed in Read and Jeffree 1991). Samples are not dehydrated but are first placed into subcooled nitrogen for cryofixation, fractured, and coated and internal structures are subsequently viewed with SEM on a cold stage. One limitation for this method is that it can produce a number of artifacts and cellular debris associated with freezing the sample, particularly in the xylem. Additionally, these samples cannot be re-examined after the sample is removed from the microscope.

Although traditionally used to view the external surface of an organism, both CSEM and CPD can be used to view internal 
structures by fracturing the sample (Pathan et al. 2008). However, a major drawback to this is that the fracturing occurs at points of least resistance and is not targeted toward a specific region. This makes internal observation of a predetermined region of interest, such as the region of pathogen colonization, difficult. Additionally, fractured sections have uneven topography, which often results in charging. Samples can also be hand-cut prior to using CPD, but this can be technically challenging, and the skill of the microscopist determines the specimen outcome.

We have developed a method (paraffin scanning electron microscopy [PSEM]) that allows the researcher to first view an image using light microscopy, determine the region of interest, and subsequently examine the region at high resolution using SEM. Because samples are sectioned on a microtome, the surface of samples for SEM can be evenly coated in a conductive layer of metal, reducing charging and improving SEM images. Additional samples can be recut from the same paraffin block, stained with reagents that label different structures, and viewed with a light microscope again. This allows multiple types of information to be gained from the same sample, enhancing the ability to obtain detailed information about the plant-microbe interaction. PSEM is ideal for observing plant-microbe interactions in specific cell types inside tissues. Based on the light microscope observations, the researcher knows the region in which to observe the pathogen and can more quickly find the area of interest, saving time and microscopy costs. We previously used this technique to examine colonization of Ralstonia solanacearum in tomato roots (Caldwell et al. 2017). Here we first show the advantage of PSEM compared with traditional CSEM and CPD. We then use PSEM to show that Fusarium oxysporum f. sp. lycopersici colonization is restricted in a resistant wild tomato accession. Finally, we demonstrate that the method works well in additional pathosystems, and we show Clavibacter michiganensis subsp. nebraskensis occlusions in the xylem vessels of susceptible Zea mays leaves as well as Pseudomonas syringae infection of Arabidopsis thaliana leaves.

\section{MATERIALS AND METHODS}

The utility of the PSEM method to observe plant-pathogen interactions at high resolution was tested using three different pathosystems. From each pathosystem, the internal tissue of the organ of interest (leaf, stem, or root) was examined using both light microscopy and SEM.

Plant materials and inoculation procedures. Tomato plant growth for light microscopy, PSEM, CPD, and CSEM. Solanum lycopersicum 'Hawaii7996' (H7996) and 'Ailsa Craig' seeds were surface sterilized in $30 \%$ bleach for $5 \mathrm{~min}$. Seeds were then rinsed and sown onto Propagation Mix (Sun Gro Horticulture) and grown under growth chamber conditions of a 16-h light/8-h dark cycle with a consistent temperature of $28^{\circ} \mathrm{C}$ and a relative humidity of $70 \%$. Plants were harvested and fixed at approximately 21 days of age.

Z. mays and C. michiganensis subsp. nebraskensis plant growth, inoculation, and confirmation. Z. mays DKC55-09 RIB Brand Blend from Dekalb Corn (Monsanto Company) plants were grown under greenhouse conditions of $25^{\circ} \mathrm{C}$ with $20 \%$ humidity and a 12-h light/ 12-h dark cycle. Pathogen strain C. michiganensis subsp. nebraskensis inoculum was prepared from a single isolate grown on nutrient broth yeast plates at $24^{\circ} \mathrm{C}$. The final concentration of the inoculum was $1 \times 10^{8} \mathrm{CFU} / \mathrm{ml}$. Prior to inoculation, cultures were tested with Agdia immunostrips for $C$. michiganensis subsp. michiganensis. These immunostrips cross-react with $C$. michiganensis subsp. nebraskensis (product ISK 44001; Agdia). Cultures tested positive. Plants were inoculated at the V5 stage by cutting the leaf tip of the two youngest fully expanded leaves and dipping them into inoculum for 15 s. Plants were harvested and fixed at approximately 14 days postinoculation (dpi); samples were taken from the middle of the lesion at $14 \mathrm{dpi}$.
Tomato and F. oxysporum plant growth, inoculation, and confirmation. Seeds of susceptible cultivar West Virginia700 (WV) ( $S$. pimpinellifolium) and resistant $S$. pimpinellifolium LA2093 were surface sterilized in 30\% bleach for 5 min. Seeds were then rinsed and sown onto Propagation Mix (Sun Gro Horticulture) and grown under growth chamber conditions and grown under 16-h light/8-h dark cycle with a temperature of $28^{\circ} \mathrm{C}$ and a relative humidity of $65 \%$. F. oxysporum f. sp. lycopersici strain 26202 was obtained from the Agricultural Research Service Culture Collection (U.S. Department of Agriculture Northern Regional Research Laboratory) grown on $0.5 \times$ potato dextrose agar plates at $28^{\circ} \mathrm{C}$ and made into glycerol stocks. To make inoculum, $1 \mathrm{ml}$ of $F$. oxysporum $\mathrm{f}$. sp. lycopersici glycerol stock was added to liquid $0.5 \times$ potato dextrose broth and grown at room temperature, under $24 \mathrm{~h}$ of light on an orbital shaker. After 2 days, broth was filtered through eight layers of Miracloth. The final spore concentration was $4 \times 10^{6}$ per milliliter using a hemocytometer. Thirty milliliters of inoculum or water was dispensed to the soil surrounding the stem with a serological pipette. Plants were harvested and fixed at $14 \mathrm{dpi}$. To confirm that plants were infected with $F$. oxysporum, genomic DNA was isolated from roots and stems of WV at 14 dpi with the Norgen Soil DNA Isolation Plus Kit (catalog number 64000; Norgen). Polymerase chain reaction (PCR) was performed with primers specific for the $F$. oxysporum internal transcribed spacer (ITS) sequence from Mishra et al. (2003). DNA extracted from mock-inoculated plants and water were included as negative controls.

Arabidopsis and $\mathrm{P}$. syringae plant growth and inoculations. A. thaliana 'Columbia' seeds were directly sown onto Propagation Mix (Sun Gro Horticulture) and grown under growth chamber conditions of a 12 -h light $/ 12$-h dark cycle at $23^{\circ} \mathrm{C}$ and a relative humidity of $65 \%$. Pathogen strain P. syringae pv. tomato DC3000 was streaked onto Luria-Bertani (LB) plates containing $1 \%$ agar, $50 \mu \mathrm{g} / \mathrm{ml}$ of kanamycin, and $100 \mu \mathrm{g} / \mathrm{ml}$ of rifampicin. Plates were incubated at $28^{\circ} \mathrm{C}$ for $48 \mathrm{~h}$. A single colony was placed into $5 \mathrm{ml}$ of LB broth with $50 \mu \mathrm{g} / \mathrm{ml}$ of kanamycin and $100 \mu \mathrm{g} / \mathrm{ml}$ of rifampicin incubated on an orbital shaker at $28^{\circ} \mathrm{C}$ for $24 \mathrm{~h}$ to an $\mathrm{OD}_{600}$ of 0.6 . Five microliters of this inoculum was placed into a new container containing $5 \mathrm{ml}$ of LB broth with $50 \mu \mathrm{g} / \mathrm{ml}$ of kanamycin and $100 \mu \mathrm{g} / \mathrm{ml}$ of rifampicin and incubated on an orbital shaker at $28^{\circ} \mathrm{C}$ for $24 \mathrm{~h}$. The final concentration of the inoculum was adjusted to $1 \times 10^{8} \mathrm{CFU} / \mathrm{ml}$ using sterile water. Plants were inoculated at age 4 weeks. The abaxial side of the leaf was infiltrated with $1 \mathrm{ml}$ of inoculum; plants were returned to growing conditions for $48 \mathrm{~h}$ and then harvested for fixation. Plants were not exhibiting symptoms at the time of sample harvest.

Histological procedures. Fixation. Two to three milliliters of primary fixative solution (1.5\% glutaraldehyde and $2 \%$ paraformaldehyde in $0.1 \mathrm{M}$ of cacodylate buffer) was placed into a glass scintillation vial. Tissue was harvested and immediately placed into the scintillation vial with the primary fixative solution. Sample size was limited to 2 to $5 \mathrm{~mm}$ to ensure penetration of the fixative into the tissue. The scintillation vial (without the lid) was placed into a vacuum desiccator and low vacuum pressure was applied for $2 \mathrm{~h}$. Samples were removed from the vacuum desiccator after $2 \mathrm{~h}$ by slowly releasing the vacuum pressure. The fixative was removed with a fine-tip disposable transfer pipette without touching the sample. Spent fixative was removed and replaced with 2 to $3 \mathrm{ml}$ of wash buffer $(0.1 \mathrm{M}$ of cacodylate, $\mathrm{pH}$ 6.8). The sample was not permitted to dry out between liquid changes. The scintillation vial without the lid was placed into a vacuum desiccator for $15 \mathrm{~min}$ and low vacuum pressure was applied. After $15 \mathrm{~min}$, the samples were removed from the vacuum desiccator by releasing the vacuum pressure slowly. Spent wash buffer was removed and replaced with fresh wash buffer. The sample was rinsed with wash buffer a total of three times.

Dehydration. Spent wash buffer was immediately replaced with 2 to $3 \mathrm{ml}$ of $25 \%$ ethanol $(\mathrm{EtOH})$ solution. The scintillation vial 
without the lid was placed into a vacuum desiccator for $15 \mathrm{~min}$ and low vacuum pressure was applied. After $15 \mathrm{~min}$, the samples were removed from the vacuum desiccator by releasing the vacuum pressure slowly. Spent $25 \% \mathrm{EtOH}$ solution was removed and replaced with fresh $50 \%$ EtOH solution. The scintillation vial (without the lid) was placed into a vacuum desiccator for $15 \mathrm{~min}$ and low vacuum pressure was applied. After $15 \mathrm{~min}$, the samples were removed from the vacuum desiccator by releasing the vacuum pressure slowly. This process was repeated with tert-butyl alcohol (TBA) solutions I to V: TBA I $\left(40 \% \mathrm{H}_{2} \mathrm{O}, 50 \% \mathrm{EtOH}, 10 \% \mathrm{TBA}\right)$, TBA II $\left(30 \% \mathrm{H}_{2} \mathrm{O}, 50 \%\right.$ EtOH, $20 \%$ TBA), TBA III ( $15 \% \mathrm{H}_{2} \mathrm{O}, 50 \%$ EtOH, 35\% TBA), TBA IV (45\% EtOH, 55\% TBA), and TBA V (25\% EtOH, 75\% TBA). Spent TBA V was removed and replaced with $100 \%$ TBA and the lid was replaced securely. The scintillation vial was placed on top of the paraffin oven to keep it warm for 24 h. After 24 h, spent $100 \%$ TBA was replaced with fresh $100 \%$ TBA. This was repeated a total of three times to ensure that all water was removed from the sample prior to the next step.
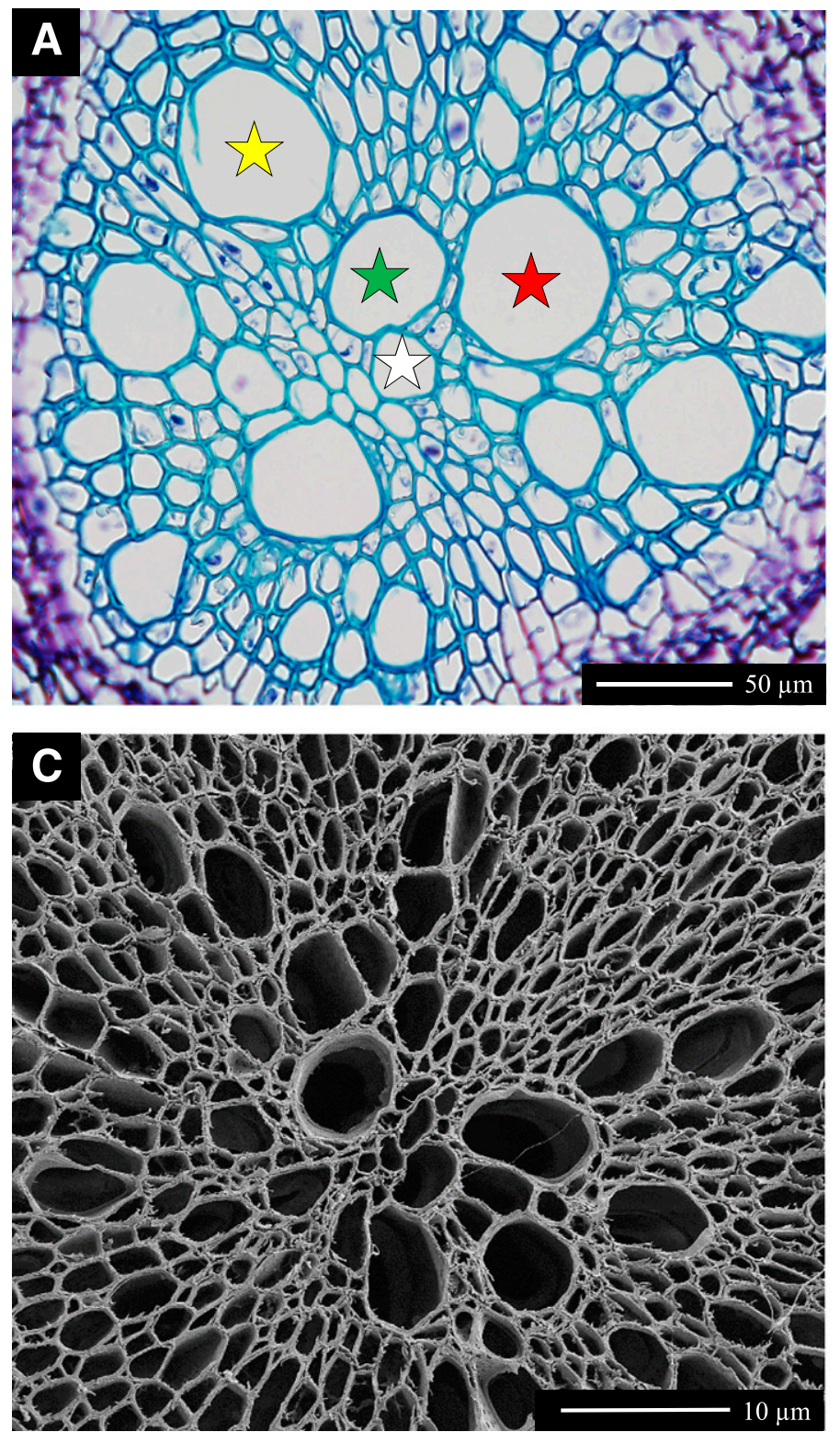

Infiltration. Spent TBA was replaced with enough fresh $100 \%$ TBA to cover the sample and the remainder of the scintillation vial was filled with melted paraffin wax. The lid was replaced and the scintillation vial was incubated at $54^{\circ} \mathrm{C}$ for $24 \mathrm{~h}$. During this time, the paraffin melted and mixed with the TBA. The lid was removed and the vial was incubated in a $54^{\circ} \mathrm{C}$ oven for $24 \mathrm{~h}$. During this time, the sample was always completely covered with paraffin wax. After $24 \mathrm{~h}$, paraffin/TBA was poured out and replaced with fresh melted paraffin. The vial was incubated without the lid at $54^{\circ} \mathrm{C}$ for $24 \mathrm{~h}$. This step was repeated a minimum of three times.

Embedding. A glass Petri dish was warmed on a $100^{\circ} \mathrm{C}$ heating plate. Paraffin in the vial was exchanged with fresh paraffin and poured into the glass Petri dish using a plain wood applicator to move the fluid and samples without causing any harm to the tissue. A Peel-Away disposable embedding mold was filled with fresh paraffin wax. Fine-tipped forceps were used to scoop the sample into the mold. The sample was placed standing perpendicular in the mold. The block was allowed to cool at room temperature for $24 \mathrm{~h}$.
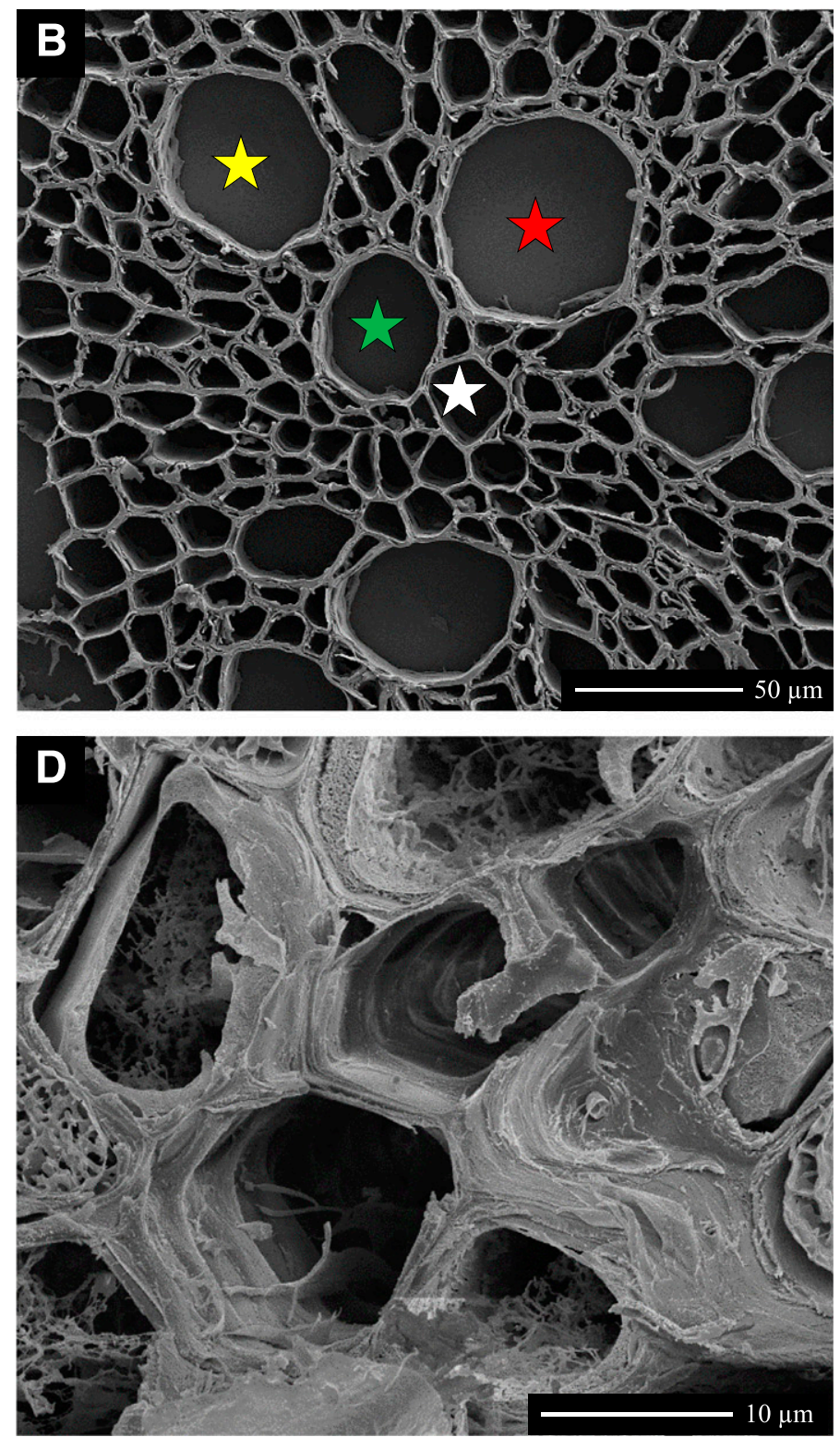

Fig. 1. Comparison of micrographs using different microscopy techniques. A, Light image of a cross-section of a root from Solanum lycopersicum 'Ailsa Craig'. B, Paraffin scanning electron microscopy image of the same sample as in A at 1,220x magnification. Stars of the same color or shade represent the same cell in A and B. C, Critical point drying image of a root from S. lycopersicum 'Hawaii7996' (H7996) at 622× magnification. D, Cryo-scanning electron microscopy (CSEM) image of a cross-section of a root from H7996 at 7,028× magnification. Note the extra noise and thickness in the CSEM image. Scale bar $=50 \mu \mathrm{m}$ in A and B and $10 \mu \mathrm{m}$ in $\mathrm{C}$ and $\mathrm{D}$. 
Mounting. The Peel-Away mold was removed from the paraffin block. The base of the block was mounted into Tissue Tek Embedding rings. A wood-burning tool (Plaid; Walmart) with a flat attachment was used to melt around the base of the block where it met the ring so that it was solidly attached to the ring. The block was allowed to cool for $24 \mathrm{~h}$ at room temperature. The block was trimmed with a single-edge razor blade to form a trapezoid on the block surface around the sample.

Sectioning. The block was cut until a smooth surface was obtained and then samples were cut to appropriate thickness using a Leica Jung 2035 Biocut Rotary Microtome.

For CPD, samples were hand sectioned to a thickness of $1 \mathrm{~mm}$ and fixed as described above with $1.5 \%$ glutaraldehyde and $2 \%$ paraformaldehyde in $0.1 \mathrm{M}$ of cacodylate buffer and rinsed in $0.1 \mathrm{M}$ of cacodylate, $\mathrm{pH}$ 6.8. Samples were dehydrated in $25 \% \mathrm{EtOH}, 50 \%$ $\mathrm{EtOH}$, and three changes of $100 \% \mathrm{EtOH}$ under low vacuum pressure for $30 \mathrm{~min}$ each. Samples were dried in the Tousimis $931 \mathrm{critical}$ point dryer according to the manufacturer's instructions.

Light microscopy. Samples were sectioned on a rotary microtome to a thickness of 7 to $12 \mu \mathrm{m}$, depending on the pathogen and tissue. Water was placed on a glass slide sitting on a slide warmer at $40^{\circ} \mathrm{C}$. The ribbon formed when cutting the block was placed onto the water on the slide, causing the ribbon to expand. After $5 \mathrm{~min}$, the excess water was removed by placing a Whatman filter next to the ribbon and allowing the water to absorb into it. The slide was allowed to dry for $24 \mathrm{~h}$ on a $45^{\circ} \mathrm{C}$ slide warmer. Slides were deparaffinized and stained for $5 \mathrm{~min}$ in each of the following solutions: $100 \%$ xylene, $50 \%$ xylene- $50 \% \mathrm{EtOH}, 100 \% \mathrm{EtOH}, 50 \% \mathrm{EtOH}, 0.05 \%$ toluidine blue, $50 \% \mathrm{EtOH}, 100 \% \mathrm{EtOH}, 50 \%$ xylene-50\% EtOH, $100 \%$ xylene, and $100 \%$ xylene. Samples were then mounted on a glass slide coated with Permount and a coverglass was placed on top. Slides were allowed to dry for $24 \mathrm{~h}$ before being imaged on an Olympus BX43 light microscope using an Olympus DP80 Dual CCD camera.

PSEM. Samples from the same blocks used for light microscopy were sectioned on a rotary microtome to a thickness of $20 \mu \mathrm{m}$. A round coverglass was taped to a glass slide with double-stick tape and a drop of water was added to the coverglass to allow the paraffin ribbon to be floated, expand, and dried for $24 \mathrm{~h}$. Slides were deparaffinized in three changes of $100 \%$ xylene followed by $100 \%$ $\mathrm{EtOH}$ for 5 min each. The samples were removed from the EtOH and the coverglass was removed from the slide and placed on a SEM stub with double-sided tape. To reduce charging of the sample, a line of silver conductive coating was applied from the pin of the specimen holder to the coverglass. Samples were sputter coated for $90 \mathrm{~s}$ in a Cressington $208 \mathrm{HR}$ sputter coater with platinum to a thickness of $5 \mathrm{~nm}$. Samples were imaged on a NovaNano SEM 200 by FEI. All parameters including spot size, working distance, and magnifications for SEM are listed in Supplementary Table S1.

CSEM. Fresh root samples were mounted onto a slotted CSEM specimen mount with Tissue Plus O.C.T. Compound. The mount was attached to a CSEM holder and then the holder was attached to a vacuum transfer device (VTD). The samples were frozen in a slush chamber filled with liquid nitrogen and transferred to the Gatan Alto 2500 Cryo-system prechamber with the VTD. Samples were fractured with a cold knife and transferred to the SEM chamber cryostage in which the high-voltage beam was activated. The temperature was raised to $-80^{\circ} \mathrm{C}$ and samples were sublimated to the desired depth. The high-voltage beam was disengaged and the samples were transferred into the prechamber, where they were sputter coated for $2 \mathrm{~min}$. Samples were transferred back to the SEM chamber cryostage and imaged at a spot size of $3.0,5.0 \mathrm{kV}$, and a working distance of $4.4 \mathrm{~mm}$.

\section{RESULTS}

PSEM results in high-quality images of specific internal structures. An important point regarding PSEM is that because we take serial sections, the regions examined with light and PSEM will be separated by several hundred microns. For example, typically 30 serial paraffin sections are placed on a slide for light microscopy, and three slides are created. For $7 \mu \mathrm{m}$ sections, each slide contains sections that span approximately $210 \mu \mathrm{m}$, for a distance of approximately $640 \mu \mathrm{m}$ from the first to the last light section. We start by examining a section in the middle (i.e., around $300 \mu \mathrm{m}$ ); if the pathogen is observed, we move to the SEM step. If we do not observe the microbe, we move to other sections on the slide and to the other two slides. This process can take as little as $1 \mathrm{~min}$ for samples in which the pathogen is immediately obvious, to $20 \mathrm{~min}$ for sections in which finding the microbe is more challenging. Once the microbe is observed, additional sections are recut from the same block and are taken to the SEM. Importantly, because cellular organization can change within the span of several hundred microns (for example, a xylem cell can taper and a new cell begin), light and PSEM sections examined are not necessarily identical. It is often possible to see a similar pattern of cellular organization, but a cellular pattern in the SEM images that exactly matches that of the
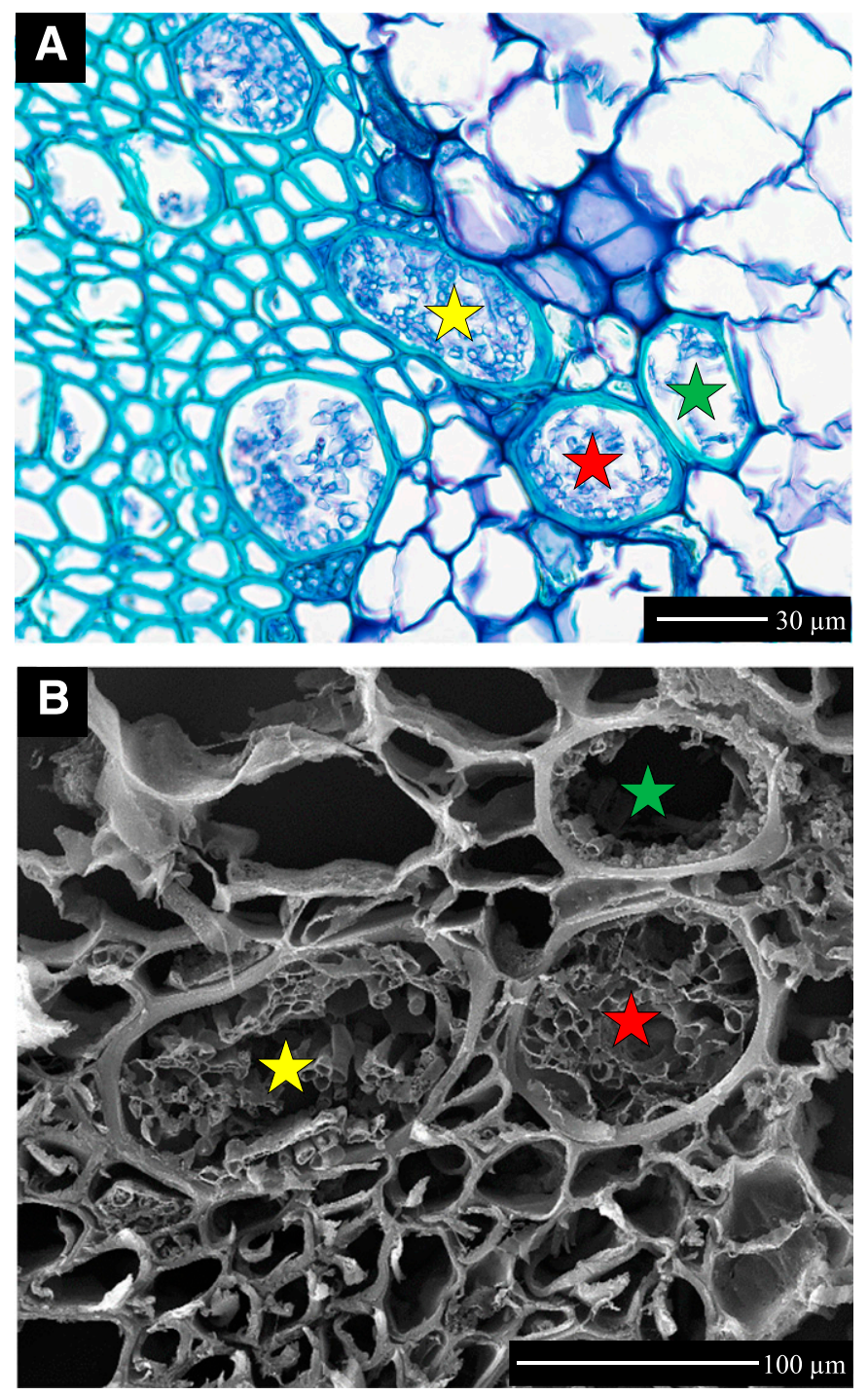

Fig. 2. Paraffin scanning electron microscopy method demonstrated with Fusarium oxysporum f. sp. lycopersici in susceptible tomato West Virginia700 stem showing hyphae in xylem vessels. A, Light microscopy at a $60 \times$ crosssection of tomato stem stained with toluidine blue. B, Same region as in A but with scanning electron microscopy (SEM) at 2,182× magnification. Stars indicate corresponding xylem vessels in A and B. Note that the image has to be rotated for the cells in light microscopy to correspond to those in SEM. Scale bar $=30 \mu \mathrm{m}$ in $\mathrm{A}$ and $100 \mu \mathrm{m}$ in $\mathrm{B}$. 
light microscopy image is not always present. However, this has not limited our ability to find the microbe in the SEM sections.

We compared images using the PSEM technique to those imaged with light microscopy, PSEM, CSEM, and CPD. Figure 1A shows light microscopy images of cross-sections from a 21-day-old tomato root grown in potting mix. Sections were stained with $0.05 \%$ toluidine blue, a polychromatic dye that stains cellular components different colors depending on their acidity. Carboxylated polysaccharides (like pectic acid) are stained purple-pink, and polyaromatic compounds like lignin or tannins are stained blue or blue-green. Thus, lignified xylem stains blue or blue-green, parenchyma cells stain a reddish purple, and phloem cells stain a reddish-pink (O'Brien et al. 1964). In Figure 1A, xylem is stained blue or bluegreen. After viewing with light microscopy, the same block was sectioned again and imaged using PSEM (Fig. 1B). Because we use the same paraffin block for PSEM, we are able to view a similar region of the sample. The section in Figure 1B is approximately $400 \mu \mathrm{m}$ from the light section in Figure 1A and therefore the cellular organization is not identical. Stars in Figure 1A and B indicate four xylem vessels that correspond between the light and SEM images. Figure $1 \mathrm{C}$ shows the CPD method using a tomato root and ambient temperature SEM, and Figure 1D demonstrates CSEM of a tomato root. Images of both CPD and CSEM are noisier than those with PSEM and the CSEM images contain additional artifacts that render it more challenging to understand what structures are present compared with PSEM.

F. oxysporum f. sp. lycopersici colonization is restricted in the resistant wild tomato accession LA2093. F. oxysporum f. sp. lycopersici is a soilborne fungus and the causal agent of Fusarium wilt. The fungus germinates on tomato roots and colonizes the root xylem (Bishop and Cooper 1983a, 1983b; Pietro et al. 2003). We inoculated resistant $S$. pimpinellifolium accession LA2093 and susceptible $S$. pimpinellifolium accession WV and examined $F$. oxysporum f. sp. lycopersici colonization in roots and shoots using PSEM. PCR with primers specific for the $F$. oxysporum ITS (Mishra et al. 2003) using DNA extracted from WV tissue at 14 dpi confirmed $F$. oxysporum f. sp. lycopersici infection in both roots and shoots (Supplementary Fig. S1). Sections were taken from the stem just above the root-shoot junction and from the primary root just below the root-shoot junction (Supplementary Fig. S2) at 14 dpi. At this time, susceptible WV plants were not wilting but were smaller than their mock-inoculated counterparts and had more
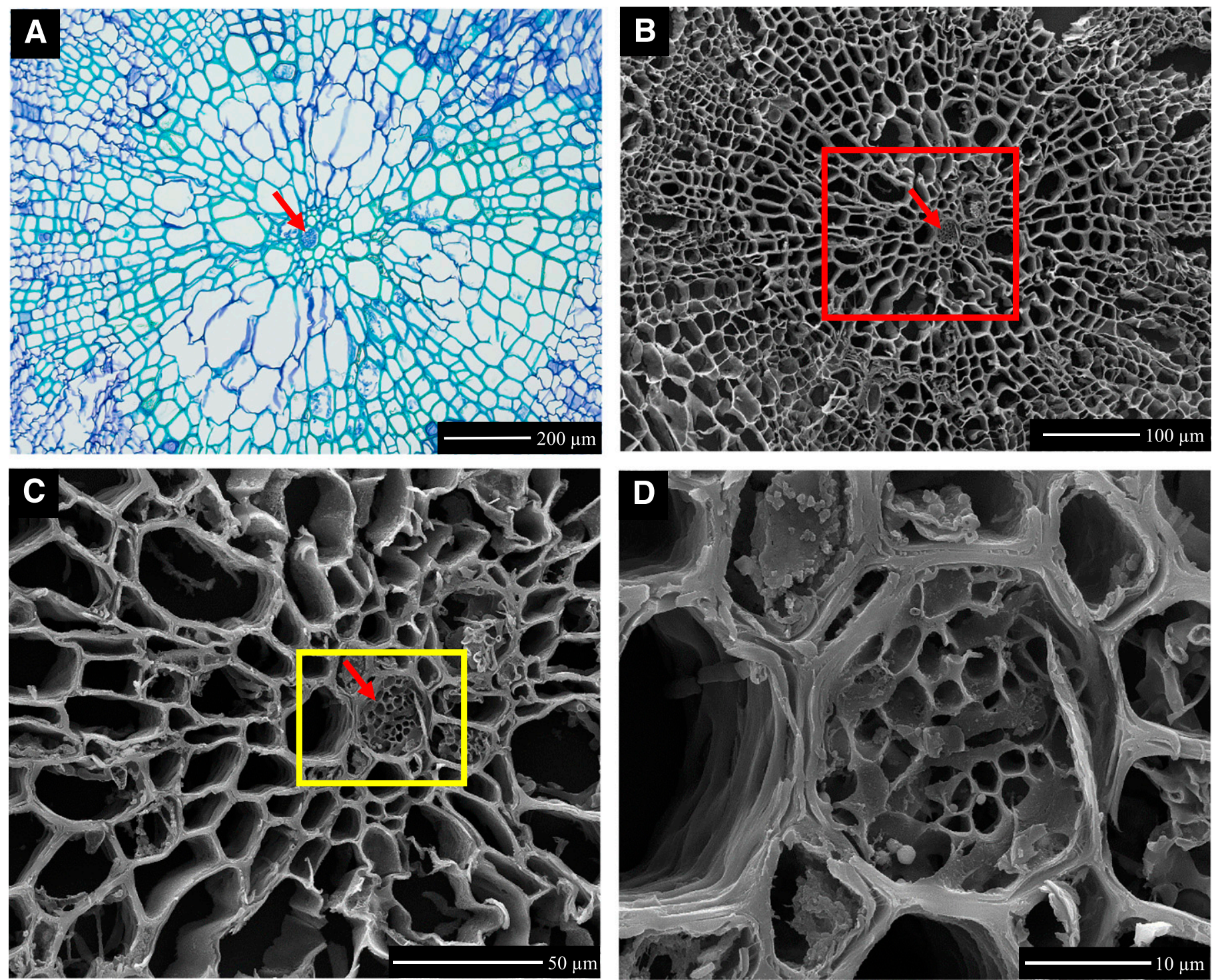

Fig. 3. Paraffin scanning electron microscopy method demonstrated with Fusarium oxysporum f. sp. lycopersici in susceptible West Virginia700 (WV) tomato root.

A, Light microscopy cross-section of WV root at 10x magnification. B, Scanning electron microscopy image at $486 \times$ magnification of the same region as A. C, Higher-magnification image of the box in B. Arrow points to F. oxysporum f. sp. lycopersici hyphae. D, Higher-magnification image of the region shown in the box in C. F. oxysporum f. sp. lycopersici hyphae fill the xylem vessel. Arrows point to the cell with hyphae in each image. Scale bar $=200 \mu \mathrm{m}$ in A, $100 \mu \mathrm{m}$ in B, $50 \mu \mathrm{m}$ in $\mathrm{C}$, and $10 \mu \mathrm{m}$ in $\mathrm{D}$. 
anthocyanin and chlorosis (Supplementary Fig. S3). LA2093 F. oxysporum f. sp. lycopersici-inoculated plants looked healthy.

In 9 of $11 \mathrm{WV}$ plants, $F$. oxysporum $\mathrm{f}$. sp. lycopersici hyphae were observed in xylem vessels in the stem and root (Figs. 2, 3, and 4). Occasionally, what first appeared to be spores in the xylem vessels in the stem when viewed through light microscopy (Fig. 2A) were
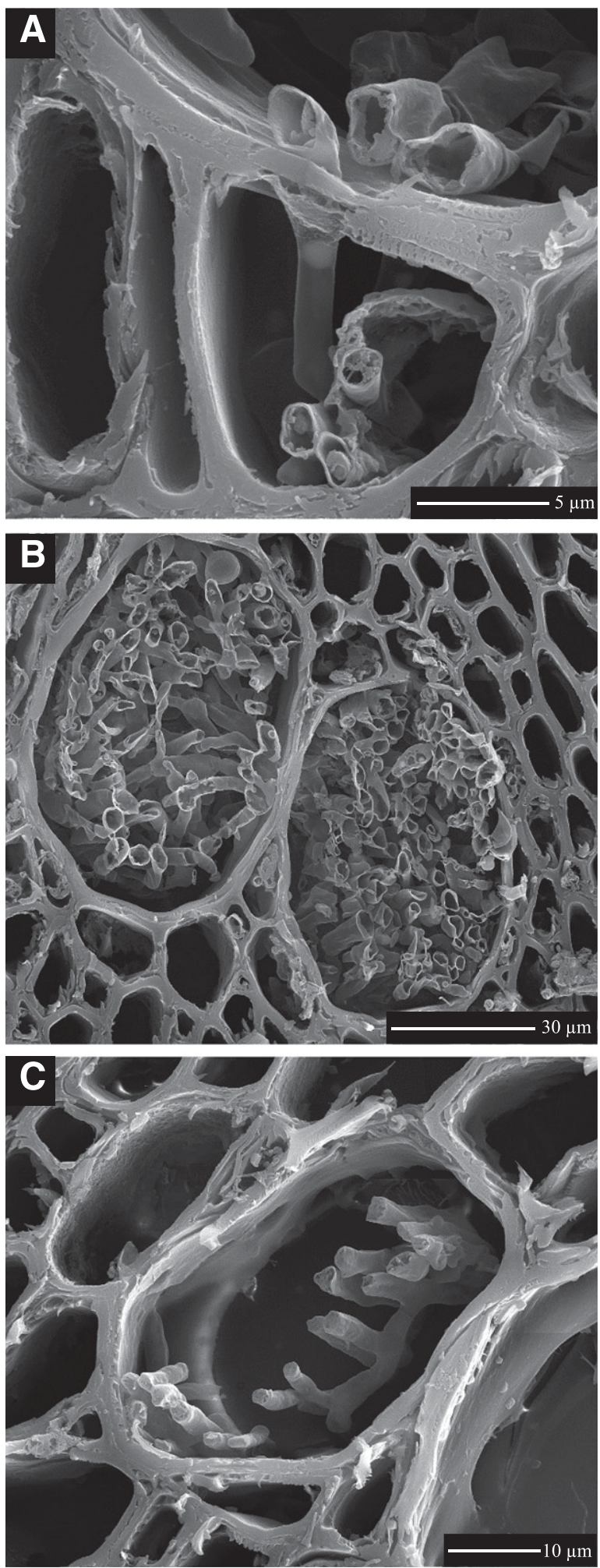

Fig. 4. Scanning electron microscopy images of Fusarium oxysporum f. sp. lycopersici hyphae in susceptible West Virginia700 stems. A, F. oxysporum f. sp. lycopersici hyphae moving through xylem vessel walls at $14,203 \times$ magnification. B, Hyphae completely occluding some xylem vessels at 2,435x magnification. C, Hyphae branching within vessels at 4,608× magnification. Scale bar $=5 \mu \mathrm{m}$ in A, $30 \mu \mathrm{m}$ in B, and $10 \mu \mathrm{m}$ in C. found to be transverse sections of hyphae when observed with PSEM (Fig. 2B). In the root, hyphae were observed completely occluding a xylem vessel (Fig. 3). Upon further examination with PSEM, hyphae were seen moving from one xylem element to
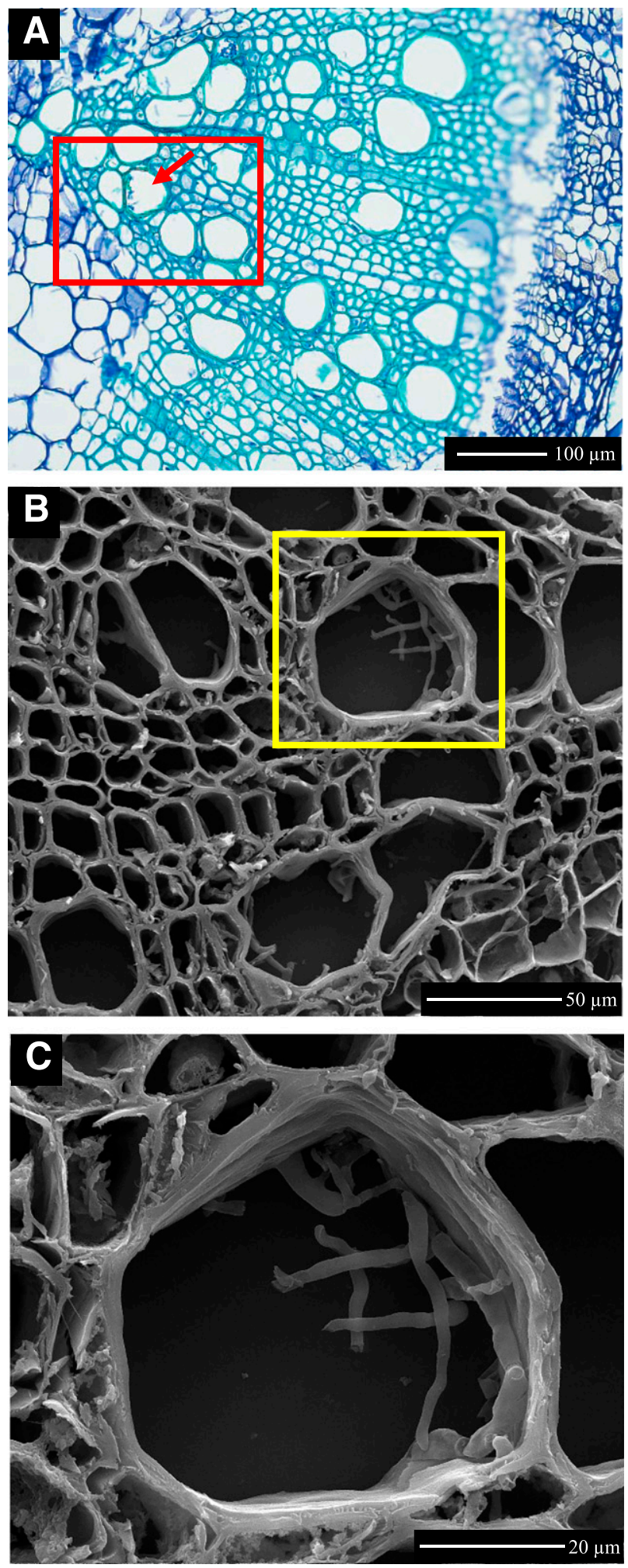

Fig. 5. Paraffin scanning electron microscopy method demonstrated with Fusarium oxysporum f. sp. lycopersici in the stem of resistant Solanum pimpinellifolium LA2093. A, Light microscopy cross-section of LA2093 stem vasculature at 20x magnification; the box indicates the region of interest with the arrow pointing to a cell with $F$. oxysporum f. sp. lycopersici. B, Scanning electron microscopy (SEM) image at $1,302 \times$ magnification of fungal hyphae growing in a xylem vessel cell. C, SEM image at 3,555x magnification of the region of the box in B showing a closer image of hyphae in a xylem vessel. Scale bar $=100 \mu \mathrm{m}$ in A, $50 \mu \mathrm{m}$ in B, and $20 \mu \mathrm{m}$ in C. 

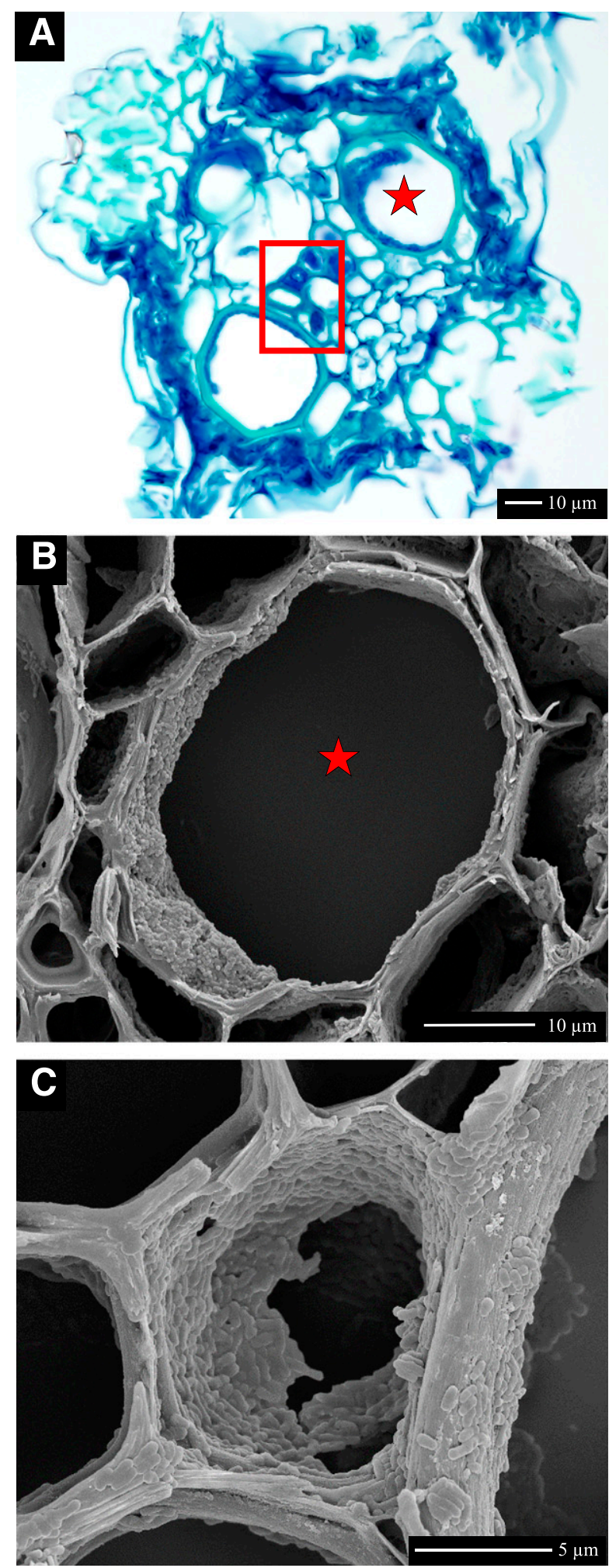

Fig. 6. Paraffin scanning electron microscopy method demonstrated with Goss's wilt-susceptible Zea mays hybrid DeKalb DKC55-09 inoculated with Clavibacter michiganensis subsp. nebraskensis. A, Light microscopy crosssection of the leaf vein viewed. The star indicates the region in B and the box indicates the region viewed in $\mathrm{C}, 40 \times$ magnification. B, Scanning electron microscopy (SEM) image at 5,644× magnification of a larger tracheary element with bacteria along the surface. The star indicates the same vessel as in A. C, SEM image at 14,002× magnification of a smaller xylem vessel with large deposits of $C$. michiganensis subsp. nebraskensis creating a blockage. The box in A indicates the region examined at higher resolution with SEM. Scale bar $=10 \mu \mathrm{m}$ in $\mathrm{A}$ and $\mathrm{B}$ and $5 \mu \mathrm{m}$ in $\mathrm{C}$. another in the xylem vessels of the stem (Fig. 4A) and could be found extending across xylem cells (Fig. 4). Hyphae were occasionally found to completely occlude xylem vessels (Fig. 4B) or to branch within the xylem vessel (Fig. 4C) in WV.

In contrast to susceptible WV, F. oxysporum $\mathrm{f}$. sp. lycopersici was observed colonizing fewer plants of resistant LA2093. F. oxysporum f. sp. lycopersici hyphae were not observed in any of the roots from the five plants examined. Because we had not observed $F$. oxysporum f. sp. lycopersici in our root sections, we did not expect to find it in any stem samples; however, in two of five plants, $F$. oxysporum f. sp. lycopersici hyphae were observed in xylem vessels in the stem. Had we examined additional regions of the root or additional sections of root segments, we likely would have observed $F$. oxysporum $\mathrm{f}$. sp. lycopersici hyphae in at least some root samples. Compared with susceptible WV, fewer $F$. oxysporum f. sp. lycopersici hyphae colonized xylem vessels in LA2093. In addition, hyphae never fully occluded cells, and they rarely stretched fully across cells. Frequently, what appeared to be hyphal fragments were observed (Fig. 5). Unlike susceptible WV, hyphae were never observed moving through a xylem cell to another cell. Taken together, these data suggest that resistant LA2093 can suppress $F$. oxysporum f. sp. lycopersici xylem vessel colonization compared with susceptible WV.

C. michiganensis subsp. nebraskensis xylem cell colonization in a susceptible maize hybrid. $C$. michiganensis subsp. nebraskensis is a gram-positive bacterium and the causal agent of Goss's bacterial wilt and leaf blight of maize (Z. mays L.), commonly known as Goss's wilt. Goss's wilt is an economically important disease in the Midwestern United States, where it can cause yield losses of up to $50 \%$ on susceptible maize hybrids (Claflin 1999). C. michiganensis subsp. nebraskensis can cause either leaf blight or systemic wilting. Leaf blight is more common and is characterized by long lesions with water soaking and darker green spots at the periphery (Jackson et al. 2007). Wilting is frequently observed when younger plants are infected. The pathogen moves systemically through the vasculature, preventing water movement and resulting in death in severe cases. C. michiganensis subsp. nebraskensis most often infects plants through wounds such as those created by wind, rain, hail, or sand (Jackson et al. 2007). The pathogen may also infect through natural openings such as stomata or trichomes (Mallowa et al. 2016). However, how $C$. michiganensis subsp. nebraskensis enters the xylem and multiplies is not well understood. We used the PSEM method to examine the xylem tissue of inoculated susceptible maize leaves at $14 \mathrm{dpi}$. Samples were taken from the middle of the lesion.

Using light microscopy, we first identified bacteria within a region of the xylem in leaves of the susceptible hybrid DKC55-09. Bacteria appeared to be concentrated in large metaxylem vessels, and it was not clear with light microscopy whether they were also found in the smaller xylem vessels (Fig. 6A, star and box indicate regions viewed in Fig. $6 \mathrm{~B}$ and $\mathrm{C}$ respectively). Using the same block, additional serial sections were cut and used for PSEM as described in the Materials and Methods. As expected from the light microscopy, bacteria were observed in large xylem vessels (Fig. 6B; the star corresponds to the xylem vessel in Fig. 6A). Examination of smaller xylem vessels revealed additional vessels filled with bacteria (Fig. 6C). The cell in Figure 6C is from the region boxed in Figure 6A, although it is not clear exactly which cell in the box in Figure 6A corresponds to that in Figure 6C.

Pseudomonas syringae pv. tomato DC3000 in Arabidopsis leaves. $P$. syringae is the causal agent of bacterial speck disease. This gram-negative, rod-shaped bacterium infects a wide range of plants, including crops such as tomato and the model plant A. thaliana. The foliar pathogen enters leaves through wounds or natural openings such as stomata. In susceptible plants, the pathogen multiplies to high levels in intracellular spaces. We syringe-infiltrated Arabidopsis leaves with $P$. syringae and harvested leaves at $48 \mathrm{~h}$ postinoculation. Plants were nonsymptomatic 
at the time of sample collection. Harvested samples were near the site of inoculation. We first examined sections using light microscopy (Fig. 7A) and found a region that appeared to contain bacteria (arrow in the inset in Fig. 7A). After observing a section with bacteria, we recut the block and used PSEM. Bacteria were found in the region observed using light microscopy as well as in additional areas of the sample that had been more challenging to view with the low resolution of light microscopy (Fig. 7D).

\section{DISCUSSION}

PSEM benefits compared with light microscopy or standard SEM. The entire PSEM process takes a little over 2 weeks from harvest to embedding, sectioning, light microscopy, resectioning, and SEM. However, using CSEM or CPD and SEM, samples can be harvested and imaged that day (CSEM) or within 2 to 3 days (CPD and SEM). What then are the benefits to using
PSEM? First, PSEM provides the ability to investigate a desired region of disease for plant-microbe interaction. Using SEM with freeze-fractured samples, the researcher can only view the sample where it fractured, which is challenging to predict and may not be in the region of interest. In contrast, using PSEM, a researcher can directly investigate specific parts of a disease phenotype (for example, lesions or specks) for microbial colonization.

Second, because samples are sectioned on a microtome in PSEM, the internal structures can be viewed easily and often with more clarity than in traditional SEM in which samples are not sectioned, hand sectioned, or fractured.

Third, although PSEM appears to take longer in terms of number of days, examining tissue with light microscopy prior to SEM can actually save time, money, and frustration. For each sample, we first serially section 90 sections and place them on three slides with 30 sections per slide for light microscopy. The time required to view these sections depends on whether the pathogen has a known cell
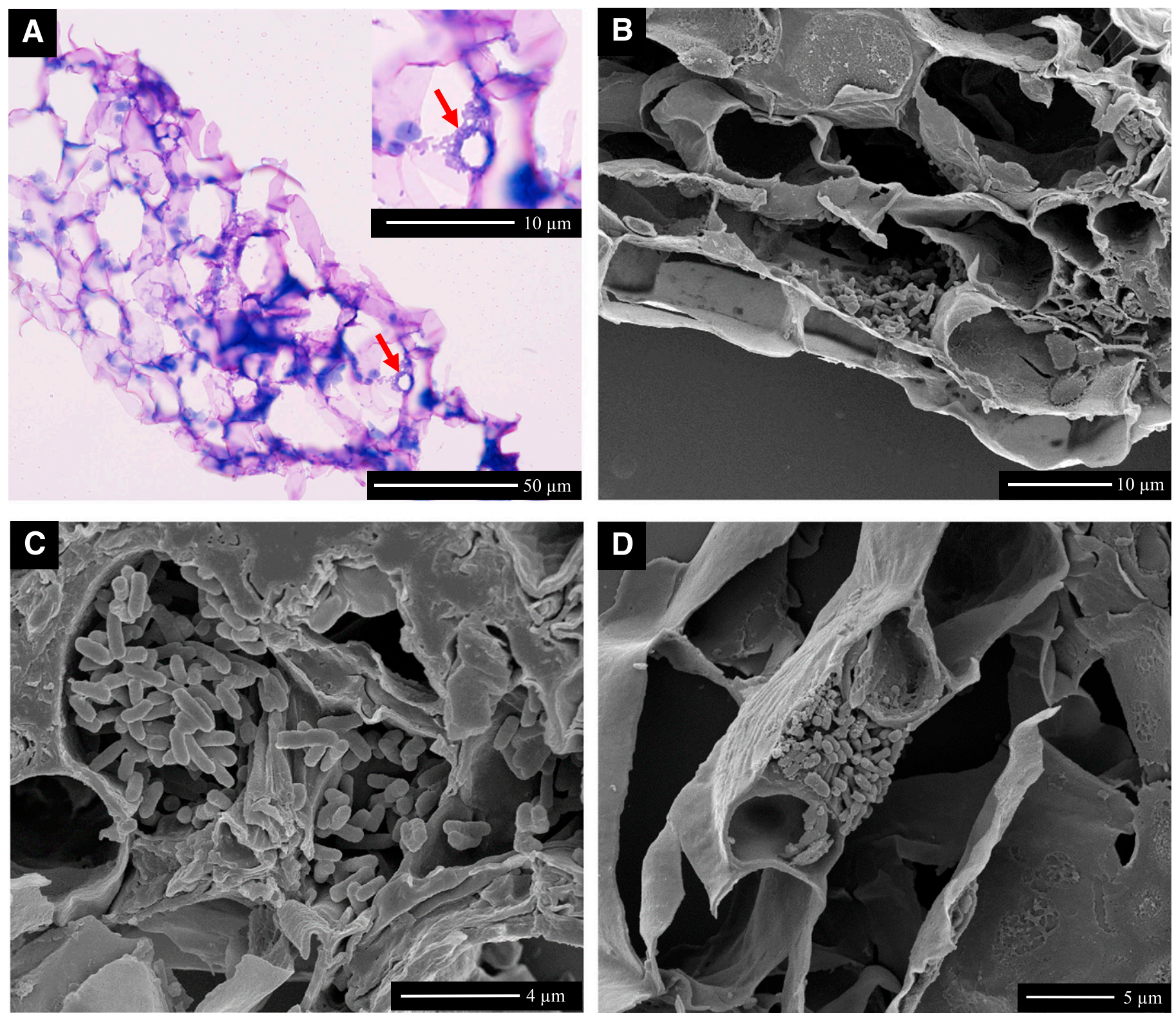

Fig. 7. Paraffin scanning electron microscopy method demonstrated with Arabidopsis thaliana leaves 2 days postinoculation with Pseudomonas syringae pv. DC3000. P. syringae is found in the intercellular air spaces and on the leaf surface. A, Light microscopy of a leaf with bacteria at $60 \times$ magnification. The inset shows a zoomed-in version with the arrow pointing to bacteria. B to D, SEM images from the same block as in A, showing the following: B, intracellular air space in the spongy parenchyma of the abaxial leaf surface at 5,466× magnification, $\mathbf{C}$, the point of leaf infiltration at $15,566 \times$ magnification, and $\mathbf{D}$, the stomata aperture filled with bacteria between its two guard cells at 9,217x magnification. Scale bar $=50 \mu \mathrm{m}$ in A, $10 \mu \mathrm{m}$ in A inset and B, $4 \mu \mathrm{m}$ in C, and $5 \mu \mathrm{m}$ in D. 
type or tissue localization (i.e., xylem-dwelling pathogens) and whether the plant is susceptible or resistant. In our experience, for xylem-dwelling pathogens in a susceptible plant, it takes only minutes using light microscopy to identify whether the pathogen is present in a given sample. The low resolution of light microscopy does not provide the necessary resolution for detailed examination of the plant-microbe interaction. Once the researcher recuts the block and moves to the PSEM, the region with the plant-microbe interaction is more easily found. For resistant plants, which can restrict or suppress pathogen colonization, it takes longer to determine whether a pathogen is present within a sample. Given that light microscopy is less expensive than SEM and that light microscopes are available in most laboratories, the knowledge that a specific sample contains a region of interest results in saving time and resources.

Finally, PSEM allows a researcher to interrogate the same sample in multiple ways and learn additional details about the plant-microbe interaction. For example, if a plant-microbe interaction of interest is observed with SEM, samples can be recut from the same paraffin block and stained with reagents that label different structures.

Although PSEM is an excellent way to investigate detailed plant-microbe interactions, the method does have limitations. First, we have found that PSEM works best with roots, stems, or thicker leaves. Acquiring high-quality sections from thin leaves, like those of Arabidopsis, is more challenging, particularly if these samples have been inoculated via syringe infiltration and thus have some damage. Second, the images observed using light microscopy are several hundred microns apart. Because serial sections are akin to traveling through developmental time, the light microscopy sections are not identical to those viewed with SEM. Initially, this can be challenging for the researcher, but with experience, we have found that localizing a similar cellular region with SEM sections becomes much easier. Finally, PSEM uses chemical fixation and sample dehydration, which may create difficulties in accurately viewing bacterial biofilms in planta. Specifically, exopolysaccharide (EPS) produced by bacteria in biofilms can be distorted by chemical fixatives such as glutaraldehyde and paraformaldehyde, and the subsequent dehydration process can create artifacts such that the EPS polymers collapse (Fassel and Edmiston 1999; Little et al. 1991; Ratnayake et al. 2012). If a researcher is specifically interested in examining biofilms at cell-type resolution, prefixing with a lysine-based fixative (such as in Ratnayake et al. 2012) may be used for PSEM. Alternatively, other techniques like transmission electron microscopy (TEM) (Palsdottir et al. 2009) or environmental SEM (Priester et al. 2007) may be used.

F. oxysporum f. sp. lycopersici colonization is restricted in a resistant wild tomato accession. We used the PSEM method to investigate $F$. oxysporum $\mathrm{f}$. sp. lycopersici colonization in resistant and susceptible accessions of the wild tomato relatives of $S$. pimpinellifolium. In susceptible plants, $F$. oxysporum $\mathrm{f}$. sp. lycopersici colonization eventually results in damage of the xylem vessels, leading to brown vascular tissue in the stem, plant wilting, and death (Pietro et al. 2003). As with other wilt diseases, xylem colonization is a key aspect of pathogen virulence. Understanding the cellular spatial dynamics of xylem colonization in crop roots may be important for understanding the contribution of specific F. oxysporum f. sp. lycopersici Fol genes to virulence, or to understand plant resistance mechanisms.

Accession LA2093 has been described for its good horticultural traits and stress tolerance (Sharma et al. 2008). Using the PSEM method, we found that LA2093 suppresses colonization of F. oxysporum f. sp. lycopersici, both in terms of fewer plants colonized and less hyphae in infected cells (Fig. 5). This is consistent with other interactions between resistant plants and $F$. oxysporum formae speciales. For example, in bean, resistant cultivars show decreased xylem colonization and impaired upward movement of F. oxysporum f. sp. phaseoli in the xylem (Garcés-Fiallos et al.
2017), while a highly virulent strain was found to reach the vasculature faster than a less virulent strain (Nino-Sanchez et al. 2015). In chickpea, resistant cultivars showed suppressed colonization of $F$. oxysporum f. sp. cicero compared with the susceptible cultivar (Upasani et al. 2016).

In susceptible WV, hyphae were typically arranged parallel to the xylem vessel and often appeared to be close to cell walls or to fill the xylem vessel. Hyphae were also observed to branch while in vessels. These observations are consistent with previous observations using TEM or SEM to view $F$. oxysporum f. sp. lycopersici in a susceptible tomato cultivar (Bishop and Cooper 1983a; Gbaja 1982).

In contrast to other studies (Bishop and Cooper 1983a, 1983b; Di Pietro et al. 2001; Gbaja 1982; Lagopodi et al. 2002; Olivain and Alabouvette 1999), we never observed hyphae in the cortex cells of either the resistant or susceptible plant at $14 \mathrm{dpi}$. This could be because we took samples close to the root-shoot junction. $F$. oxysporum f. sp. lycopersici first invades the root epidermis and cortex and subsequently moves to the vasculature where movement toward the shoot can occur (Olivain and Alabouvette 1999).

In conclusion, the PSEM method provides a way to view plantpathogen interactions at cell-type resolution, reduces noise in the SEM, and allows the researcher to examine specific regions of disease as well as sections from the same sample block in different ways. We found it to be ideally suited to examine colonization and localization of xylem-dwelling pathogens; as demonstrated here, the technique also works well for multiple plant organs and pathosystems.

\section{ACKNOWLEDGMENTS}

We thank K. Gans with technical help with $C$. michiganensis subsp. nebraskensis inoculations, $\mathrm{K}$. Wise for maize plants and C. michiganensis subsp. nebraskensis cultures, M. A. Webb for technical help during early stages of the project, and R. Hiles for comments on the manuscript.

\section{LITERATURE CITED}

Anderson, T. F. 1951. Techniques for the preservation of three-dimensional structure in preparing specimens for the electron microscope. Trans. N. Y. Acad. Sci.: 130-134.

Bishop, C. D., and Cooper, R. M. 1983a. An ultrastructural study of vascular colonization in three vascular wilt diseases I. Colonization of susceptible cultivars. Physiol. Plant Pathol. 23:323-343.

Bishop, C. D., and Cooper, R. M. 1983b. An ultrastructural study of root invasion in three vascular wilt diseases. Physiol. Plant Pathol. 22:15-27.

Caldwell, D., Kim, B. S., and Iyer-Pascuzzi, A. S. 2017. Ralstonia solanacearum differentially colonizes roots of resistant and susceptible tomato plants. Phytopathology 107:528-536.

Claflin, L. E. 1999. Goss's bacterial wilt and blight. Pages 4-5 in: Compendium of Corn Diseases, 3rd ed. D. G. White, ed. American Phytopathological Society, St. Paul, MN.

Di Pietro, A., García-MacEira, F. I., Méglecz, E., and Roncero, M. I. 2001. A MAP kinase of the vascular wilt fungus Fusarium oxysporum is essential for root penetration and pathogenesis. Mol. Microbiol. 39:1140-1152.

Fassel, T. A., and Edmiston, C. E. 1999. Bacterial biofilms: Strategies for preparing glycocalyx for electron microscopy. Methods Enzymol. 310: 194-203.

Fritschi, F. B., Lin, H., and Walker, M. A. 2008. Scanning electron microscopy reveals different response pattern of four Vitis genotypes to Xylella fastidiosa infection. Plant Dis. 92:276-286.

Garcés-Fiallos, F. R., de Borba, M. C., Schmidt, É. C., Bouzon, Z. L., and Stadnik, M. J. 2017. Delayed upward colonization of xylem vessels is associated with resistance of common bean to Fusarium oxysporum f. sp. phaseoli. Eur. J. Plant Pathol. 149:477-489.

Gbaja, I. S. 1982. Scanning electron microscopy of tomato plants colonized by Fusarium oxysporum f. sp. lycopersici. Trans. Br. Mycol. Soc. 79:540-542.

Jackson, T. A., Harveson, R. M., and Vidaver, A. K. 2007. Reemergence of Goss's wilt and blight of corn to the Central High Plains. Plant Health Prog. 8:44.

Koutsoudis, M. D., Tsaltas, D., Minogue, T. D., and von Bodman, S. B. 2006. Quorum-sensing regulation governs bacterial adhesion, biofilm development, and host colonization in Pantoea stewartii subspecies stewartii. Proc. Natl. Acad. Sci. USA 103:5983-5988. 
Lagopodi, A. L., Ram, A. F. J., Lamers, G. E. M., Punt, P. J., Van den Hondel, C. A. M. J. J., Lugtenberg, B. J. J., and Bloemberg, G. V. 2002. Novel aspects of tomato root colonization and infection by Fusarium oxysporum f. sp. radicislycopersici revealed by confocal laser scanning microscopic analysis using the green fluorescent protein as a marker. Mol. Plant-Microbe Interact. 15:172-179.

Little, B., Wagner, P., Ray, R., Pope, R., and Scheetz, R. 1991. Biofilms: An ESEM evaluation of artifacts introduced during SEM preparation. J. Ind. Microbiol. 8:213-221.

Mallowa, S. O., Mbofung, G. Y., Eggenberger, S. K., Den Adel, R. L., Scheiding, S. R., and Robertson, A. E. 2016. Infection of maize by Clavibacter michiganensis subsp. nebraskensis does not require severe wounding. Plant Dis. 100:724-731.

Mbofung, G. C. Y., Sernett, J., Horner, H. T., and Robertson, A. E. 2016. Comparison of susceptible and resistant maize hybrids to colonization by Clavibacter michiganensis subsp. nebraskensis. Plant Dis. 100:711-717.

Mishra, P. K., Fox, R. T., and Culham, A. 2003. Development of a PCR-based assay for rapid and reliable identification of pathogenic Fusaria. FEMS Microbiol. Lett. 218:329-332.

Nino-Sanchez, J., Tello, V., Casado-del Castillo, V., Thon, M. R., Benito, E. P., and Diaz-Minguez, J. M. 2015. Gene expression patterns and dynamics of the colonization of common bean (Phaseolus vulgaris L.) by highly virulent and weakly virulent strains of Fusarium oxysporum. Front. Microbiol. 6:234.

O'Brien, T. P., Feder, N., and McCully, M. E. 1964. Polychromatic staining of plant cell walls by toluidine blue O. Protoplasma 59:368-373.

Olivain, C., and Alabouvette, C. 1999. Process of tomato root colonization by a pathogenic strain of Fusarium oxysporum $\mathrm{f}$. sp. lycopersici in comparison with a non-pathogenic strain. New Phytol. 141:497-510.

Palsdottir, H., Remis, J. P., Schaudinn, C., O’Toole, E., Lux, R., Shi, W., McDonald, K. L., Costerton, J. W., and Auer, M. 2009. Three-dimensional macromolecular organization of cryofixed Myxococcus xanthus biofilms as revealed by electron microscopic tomography. J. Bac. 191:2077-2082.

Pathan, A. K., Bond, J., and Gaskin, R. E. 2008. Sample preparation for scanning electron microscopy of plant surfaces-Horses for courses. Micron 39:1049-1061.

Pietro, A. D., Madrid, M. P., Caracuel, Z., Delgado-Jarana, J., and Roncero, M. I. G. 2003. Fusarium oxysporum: Exploring the molecular arsenal of a vascular wilt fungus. Mol. Plant Pathol. 4:315-325.

Priester, J. H., Horst, A. M., Van De Werfhorst, L. C., Saleta, J. L., Mertes, L. A. K., and Holden, P. A. 2007. Enhanced visualization of microbial biofilms by staining and environmental scanning electron microscopy. J. Microbiol. Methods 68:577-587.

Ratnayake, K., Joyce, D. C., and Webb, R. I. 2012. A convenient sample preparation protocol for scanning electron microscope examination of xylem-occluding bacterial biofilm on cut flowers and foliage. Sci. Hortic. (Amsterdam) 140:12-18.

Read, N. D., and Jeffree, C. E. 1991. Low-temperature scanning electron microscopy in biology. J. Microsc. 161:59-72.

Sharma, A., Zhang, L., Niño-Liu, D., Ashrafi, H., and Foolad, M. R. 2008. A Solanum lycopersicum $\times$ Solanum pimpinellifolium linkage map of tomato displaying genomic locations of R-genes, RGAs, and candidate resistance/ defense-response ESTs. Intl. J. Plant Genom. 2008:1-18.

Sun, Q., Sun, Y., Walker, M. A., and Labavitch, J. M. 2013. Vascular occlusions in grapevines with Pierce's disease make disease symptom development worse. Plant Physiol. 161:1529-1541.

Upasani, M. L., Gurjar, G. S., Kadoo, N. Y., and Gupta, V. S. 2016. Dynamics of colonization and expression of pathogenicity related genes in Fusarium oxysporum f.sp. ciceri during chickpea vascular wilt disease progression. PLoS One 11:e0156490. 